\title{
Biocomposite Materials of Eleocharis dulcis Fibers with Iron (III) Nanoparticles and Its Potential for Sasirangan Textile Wastewater Treatment
}

\author{
Chairul Irawan ${ }^{\#}$, Iryanti Fatyasari Nata ${ }^{\#}$, Meilana Dharma Putra ${ }^{\#}$, Muthia Elma ${ }^{\#}$, Khairul Fauziah Hanisa ${ }^{\#}$ \\ ${ }^{\#}$ Department of Chemical Engineering, Faculty of Engineering, Lambung Mangkurat University, \\ Banjarbaru, South Kalimantan 70714, Indonesia \\ E-mail: cirawan@unlam.ac.id,ifnata@unlam.ac.id,mdputra@unlam.ac.id,melma@unlam.ac.id, f.hanisa28@gmail.com
}

\begin{abstract}
Eleocharis dulcis (Chinese water chestnut), locally Kalimantan named Purun Tikus, is a plant that grows in highly acidic swamps areas in South Kalimantan. Eleocharis dulcis(ED), was usually used as a material for traditional handicrafts. Therefore it is necessary for develop and innovate to convert the material becomes valuables. This research focuses on the study of biocomposite nanoparticles of $\mathrm{ED}$ and its potentials as an adsorbent to reduce the concentration of $\mathrm{Pb}^{2+}$ ions, Total Suspended Solid (TSS) and color from Sasirangan textile industry wastewater. The synthesis of the biocomposite nanocomposite was made by solvothermal synthesis. Firstly, ED stems dried was cut to small size (250 microns), then through the de-lignification process to eliminate lignin by $1 \% \mathrm{w} / \mathrm{v} \mathrm{NaOH}$ solution. ED de-lignification put into a hydrothermal reactor, right afterward was carried out by one-pot solvothermal reaction of 1,6-diaminohexane, iron (III) chloride hexahydrate, and ethylene glycol at $200{ }^{\circ} \mathrm{C}$ for $6 \mathrm{~h}$.The process was produced two types of biocomposites, without the amino group (EDB-M) and the amino group (EDB-MH). The characterization results shown by SEM, magnetic nanoparticles have been formed on the surface of ED fiber.The ED biocomposite nanoparticles (EDB) with diameter size around 30-50 nm could be obtained. X-Ray Diffraction (XRD) analysis showed treatment of EDdelignification was increased the porosity of the fiber, shown by increased Crystallinity Index (CrI) about 72.75\%. The biocomposites adsorbent, EDB-M, and EDBMH had adsorption capacity for $\mathrm{Pb}^{2+}$ ions about $44.21 \mathrm{mg} / \mathrm{g}$ and $55.62 \mathrm{mg} / \mathrm{g}$ at equilibrium $\mathrm{pH}(\mathrm{pH}$ ) of 6 and equilibrium time of 2 hours. The effectiveness of reduced TSS was about of $91.9 \%$ and $98.1 \%$. Besides that, the colour intensity of color was decreased about $96.7 \%$ and $97.8 \%$ for the EDB-M and EDB-MH, respectively.
\end{abstract}

Keywords - adsorption; biocomposite; Eleocharis dulcis; iron (III) nanoparticle; $\mathrm{Pb}^{2+}$ ion; TSS; color

\section{INTRODUCTION}

Eleocharis dulcis (Chinese water chestnut), locally Kalimantan named Purun Tikus, is an aquatic plant that grows in highly acidic swamps areas in South Kalimantan. ED Stems are hollow, have an average diameter of $5 \mathrm{~mm}$ and growth almost to $2 \mathrm{~m}$ tall and having heavy metal uptake capacity in wetland filtration system [1]. ED is highly renewable material, abundant resources in South Kalimantan among almost of 70 acres are grown in a swamp area and it takes a few months to grow toward maturity. ED has also been customarily used to living handicrafts, such as bag, floor mat, kitchen tools, etc.

The textile industry is very flourishing in their process. It is causing a large amount of highly polluted effluent wastewater including detergents, oils, dyes, suspended solids and dissolved solids, harmful, biodegradable and nonbiodegradable substances, and alkalines substance that poses an environmental problem [2]-[4]. Considering a traditional textile in South Kalimantan, Indonesia called Sasirangan, the process including pretreatment, dyeing, printing, and finishing operation that using different types of dyes, such as: disperse, reactive, insoluble dye, etc. in the presence of additional dyeing and chemicals. Dyeing effluents from Sasirangan textile industry are highly toxic as same as other textiles industry contain a number of metal complex dyes (e.g. $\mathrm{Pb}, \mathrm{Cu}, \mathrm{Cd}$, etc), a high concentration of suspended solid (e.g TSS) and color into the receiving waters. Lead $\left(\mathrm{Pb}^{2+}\right)$ is considered detected in sasirangan textile wastewater even from dyestuff and printing process [5]. It is one of those heavy metal that toxic to humans at low concentration. It is therefore important to reduce the concentration of metal, TSS, and color in textile wastewater to meet the standard regulation before charging it into surface water and river.

Adsorption process is commonly used to eliminate color, suspended solids and metal pollutant from textile wastewater compares to other technologies such as coagulationflocculation, filtration, chemical precipitation, membrane- 
filtration, oxidation, sedimentation, biological process, etc. [2]-[6]. Activated carbon is commonly used as an adsorbent in adsorption process, however commercial activated carbon is becoming more expensive, then there is a need to find low-cost adsorbent from renewable sources. Using low-cost biosorbents such as biomass, agricultural wastes, organic and seafood processing wastes, and clay materials can be as an alternative adsorbent for textile wastewater treatment because they are inexpensive and remarkable of reducing trace levels of color, suspended solids, and heavy metal ions. However, to improve their adsorption density and enhance the adsorption kinetic, the design of and research of innovative adsorbents are still required [7].

Potential environmental impact of ED fibers utilization will be studied in this work. Since there is no information on using biocomposite of ED fibers with iron (III) nanoparticle as an adsorbent to remove $\mathrm{Pb}^{2+}$ ion, TSS, and color from textile wastewater, this research will focus on the study of a biocomposite of ED fibers with iron (III) nanoparticle as a possible alternative adsorbent for Sasirangan textile wastewater treatment. Modified of ED is promising to this alternative adsorbent for textile wastewater treatment due to abundant, renewable, potentially less expensive and readily available. Develop and converting of the ED to become a value-added product will be studied in this research. Iron and its compounds were reported can be used to chemically modify the adsorbent concerning to improve the adsorption density of metal ions and easily to separated it from the solution using magnetic [8]. Magnetic nanoparticles are well- known and prepared for their ability and can be conveniently separated to generate heat when exposed to alternating magnetic fields [9]. It has been also found that the chemical and physical properties of the ED adsorbent can be enchanted even by chemical or physical modifications treatment to make the adsorbent become effective and high capacity adsorption in composites.

This research will focus on the study of a biocomposite of ED with iron (III) nanoparticles and its potentials as an adsorbent to reduce the concentration of $\mathrm{Pb}^{2+}$ ions, TSS, and color from Sasirangan textile wastewater.

\section{MATERIALS AND METHOD}

\section{A. Materials}

Sasirangan textile wastewater was obtained directly from the factory discharge point without any treatment in Banjarmasin, South Borneo. The samples were kept stored at below $4^{\circ} \mathrm{C}$. Pure grade analysis chemicals of anhydrous sodium acetate $\left(\mathrm{C}_{2} \mathrm{H}_{3} \mathrm{NaO}_{2}\right)$, ethylene glycol anhydrous, 99.8\% $\left(\mathrm{C}_{6} \mathrm{H}_{6} \mathrm{O}_{2}\right)$, 1,6-diaminohexane $\left(\mathrm{C}_{6} \mathrm{H}_{16} \mathrm{~N}_{2}\right)$, iron (III) chloride hexahydrate $\left(\mathrm{FeCl}_{3} \cdot 6 \mathrm{H}_{2} \mathrm{O}\right)$, D-Glucose anhydrous $\left(\mathrm{C}_{6} \mathrm{H}_{2} \mathrm{O}_{6}\right)$, lead (II) nitrate, $99.9 \%\left(\mathrm{~Pb}\left(\mathrm{NO}_{3}\right)_{2}\right)$ was used as artificial $\mathrm{Pb}^{2+}$ solution, hydrochloric acid $(\mathrm{HCl})$, and natrium hydroxide $(\mathrm{NaOH})$ were obtained from MERCK. All others chemicals directly used in this work were of analytical grade without further treatment.

\section{B. Preparation of ED Biocomposites with Iron (III) Nanoparticles}

The synthesis of ED biocomposites with iron (III) nanoparticles (EDB-M) was carried out by one-pot solvothermal synthesis. Firstly, ED stem (approximately 75 $\mathrm{cm})$ was dried and be cut into small size $( \pm 25 \mathrm{~mm})$, then placed in a conical flask. The delignification process by adding $1 \% \mathrm{w} / \mathrm{v}$ of $\mathrm{NaOH}$ solution into the flask and allowed at $80^{\circ} \mathrm{C}$ for $2 \mathrm{~h}$ on a hot plate magnetic stirrer for eliminating the lignin. After $2 \mathrm{~h}$, the flask and its content were allowed to cool to ambient temperature. The delignified fibers (ED fibers) were filtered in a Buchner funnel and washed with warm distilled water until the $\mathrm{pH}$ of filtrate become neutral. Finally, the ED fibers were dried in an oven at $80^{\circ} \mathrm{C}$ for $6 \mathrm{~h}$.

Briefly, anhydrous sodium acetate (1.6 g) and iron (III) chloride hexahydrate $(0.8 \mathrm{~g})$ were dissolved in ethylene glycol anhydrous $(24 \mathrm{~mL})$ with vigorous stirring at $50{ }^{\circ} \mathrm{C}$ using magnetic stirrer with temperature control to give an orange solution. Surface amine-functionalized of iron (III) nanoparticles were synthesized adapting to the method used by [8]. The iron (III) nanoparticles composites were reacted by soaking of $0.5 \mathrm{~g}$ ED fibers into the solution, and then solvothermal was carried out at $200{ }^{\circ} \mathrm{C}$ for $6 \mathrm{~h}$ (EDB-M). When 1,6-diaminohexane $(7 \mathrm{~mL})$ was added, the mixed solution will turn into dark-orange for EDB-MH. After cooling to ambient temperature, the ED biocomposites were collected from the mixed solution by applying a magnet and was rinsed with deionized water (DI water) followed by ethanol of $70 \% \mathrm{v} / \mathrm{v}$ each for three times to eliminate the remaining chemicals. The obtained of ED biocomposites with iron (III) nanoparticles were kept in DI water for forthcoming use.

There are two types of ED biocomposites material, added and without the addition of amino group using 1,6diaminohexane. The processes were produced two types of ED biocomposites, without the amino group (EDB-M) and with the amino group (EDB-MH).

\section{Characterization of $E D B-M$ and $E D B-M H$}

Surface morphology of EDB-M and EDB-MH were characterized by field-emission scanning electron microscopy (FESEM, JOEL JSM-6500F) with energydispersive X-ray spectroscopy (EDS). The samples were coated with platinum by sputtering before the examination.

The X-ray diffraction (XRD) analysis was carried out on Rigaku n D/MAX-BX-ray diffractometer by using Copper $\mathrm{K}$-alpha $(\mathrm{CuK} \alpha)$ radiation. The operating voltage and current were kept at $40 \mathrm{kV}$ and $100 \mathrm{~mA}$, respectively. Fourier transform infrared spectrometry (Bio-rad, Digilab FTS-3500) was used to identify the surface functional groups of the EDB-M and EDB-MH nanocomposites.

\section{Batch Mode Experiment of Sasirangan Textile Wastewater Treatment}

Batch adsorption experiments were performed by putting $50 \mathrm{~mL}$ solution of a certain amount of lead into $100 \mathrm{~mL}$ glass bottle and adjusting its $\mathrm{pH}$ value using $1 \mathrm{M} \mathrm{NaOH}$ or $\mathrm{HCl}$. Afterward, weighed the amount of the adsorbent (EDB$\mathrm{M}$ and EDB-MH, respectively) was added into a glass bottle. The mixture was then placed in a shaker with a water bath (Firstek Scientific) at a pre-determined temperature for certain contact time. The adsorption process was carried out while shaking at ambient temperature for 6 hours. At the end of the running experiment, the mixed solution was 
centrifuged and filtered by using a $0.2 \mu \mathrm{m}$ PVDF membrane (Advantec). Then, the filtrates were analysed for residual $\mathrm{Pb}^{2+}$ concentration using Inductively Coupled Plasma Optical Emission Spectrophotometer (ICP-OES, Horiba Jobin-Yvon Ultimate II). TSS values were measured by APHA standard method 2540-D [9]. The filtrates were also used for color concentration analysis using UV-Vis spectrophotometer (Shimadzu UV-2600) at the maximum absorption wavelength of $\left(\lambda_{\max }=402 \mathrm{~nm}\right)$. Adsorbed $\mathrm{Pb}^{2+}$ ion, TSS, and color were calculated from the difference between initial and equilibrium the adsorbate concentrations. The adsorption capacity of $\mathrm{Pb}^{2+}$ ion onto the adsorbent in the equilibrium, $q_{e}$ was calculated as follows:

$$
q_{\theta}=\frac{\left(c_{0}-c_{\varepsilon}\right) V}{m}
$$

where $V$ is the volume of sample solution $(\mathrm{mL}), \mathrm{m}$ is the amount of adsorbent used in this batch experiment $(\mathrm{mg})$ and $\mathrm{C}_{\mathrm{o}}(\mathrm{mg} / \mathrm{L})$ and $\mathrm{C}_{\mathrm{e}}(\mathrm{mg} / \mathrm{L})$ are initial and the equilibrium concentration of $\mathrm{Pb}^{2+}$ ion, respectively

The adsorbent was also used to investigate the $\mathrm{pH}$ equilibrium factor that affecting $\mathrm{Pb}^{2+}$, TSS, and color adsorption capacity. The others, EDB-M and EDB-MH, were separately used to finding out the correlation of amine content that has an important role in the adsorption phenomenon. The adsorption experiments were done in triplicate samples and the average value was taken.

In order to regenerate the adsorbent for repeated uses, the EDB-M and EDB-MH loaded metal ions were desorbed by shaking into $0.1 \mathrm{M} \mathrm{HCl}$ for 24 hours. After washing completely using DI water, the regenerated adsorbent was loaded for the next cycle of $\mathrm{Pb}^{2+}$, TSS and color adsorption processes. The cycles of such adsorbent were repeated for three times in triplicate analysis.

\section{RESULTS AND DISCUSSION}

\section{A. Characterization of $E D B-M$ and $E D B-M H$}

The characterization of EDB-M and EDB-MH were done by SEM, XRD, TGA, and FTIR analysis. Fig. 1 presents SEM images indicating the changes in the surface properties of the ED fibers after the treatments.

Fig. 1a shows the physical features of ED fibre structure are roughness with the lamellar shape. It is indicated ED fibres contain lignin, hemicelluloses, and other components that binding with cellulose. After delignification (Fig. 1b), the ED fibres morphology of the surface of alkaline treated ED fibres using $1 \% \mathrm{NaOH}$ solution shows the formation of the scratches by cause of the discharge of the lignin, hemicelluloses, and other components changed the characteristics of the surface morphology. It is noted that the alkaline treatment discharges the waxy and gummy substances observed in the fibers before treated [11]-[12].

This characteristic might be increased the adhesion between fibres and matrix when it is used in reinforcing composites material [10]. The ED fibers change their morphology after alkaline treatment. It's exposed for the composite easy to attach the matrix site of the ED fiber. A typical biomass from organic plants is composed of 30-50\% cellulose, 20-40\% hemicelluloses and 15-30\% lignin [13].
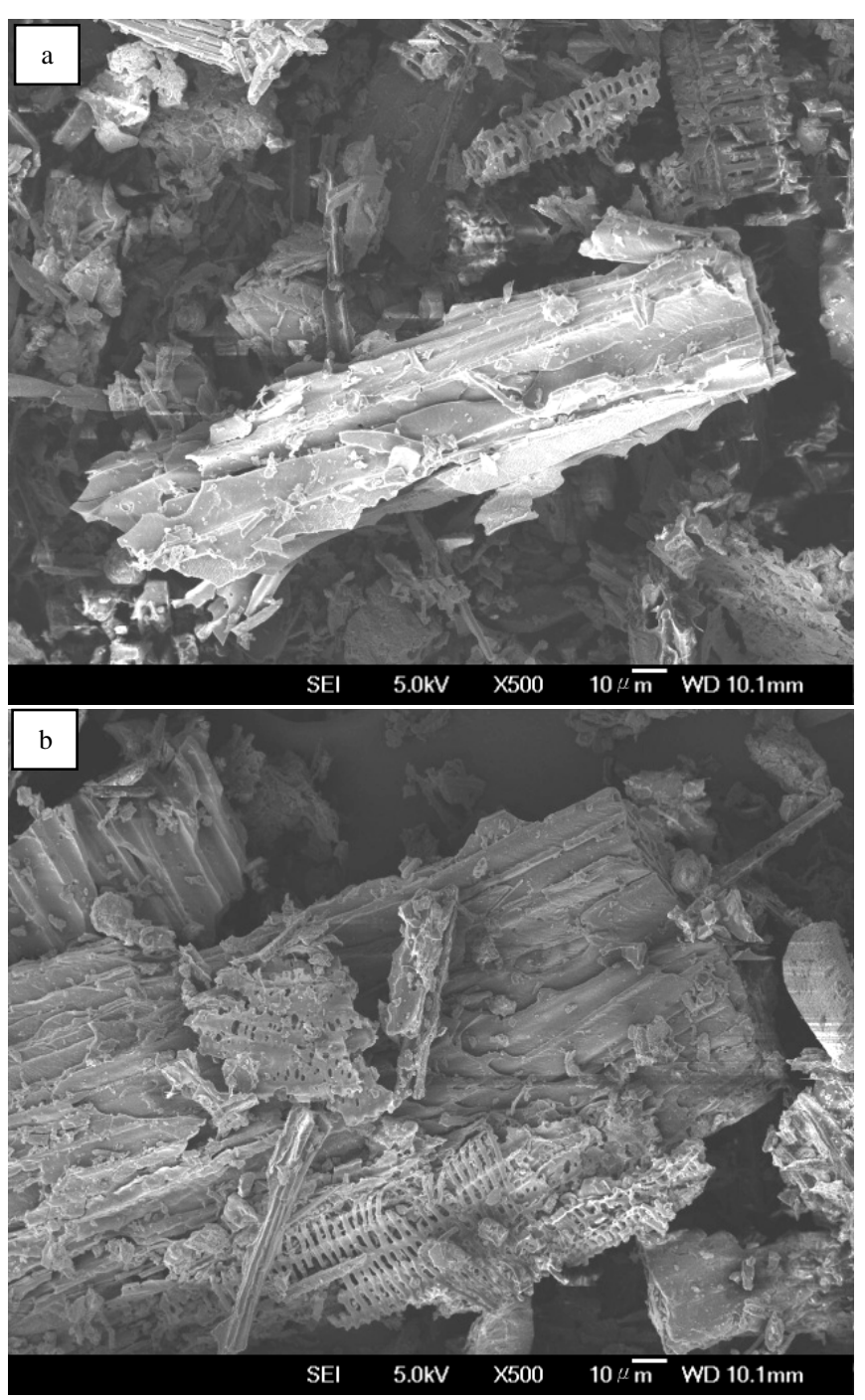

Fig. 1 FESEM image of a. ED fibers, b. ED fibers after delignifiation

Fig. 2 shows the surface texture of the treated ED fibers, ED biocomposites material, without and with the addition of amino group using 1,6-hexanediamine. The processes were produced two types of ED biocomposites, without the amino group (EDB-M) in Fig. 2a, and with the amino group (EDB$\mathrm{MH}$ ) in Fig. 2b. Recognizing the photograph, monodispersed nanoparticles were aggregated positively, which was due to the nanoparticles size of the $\mathrm{Fe}_{2} \mathrm{O}_{3}$. As shown, the surface of ED fibers is attached to iron (III) nanoparticles with diameter size around $30-50 \mathrm{~nm}$, even for EDB-M and also EDB-MH. It is also confirmed by EDX analysis that the EDB-M and the EDB-MH contain the iron component. The iron content may affect the adsorbent by enhancing the highadsorption of sorbent capacity for reactivity toward a wide range of organic pollutants [14]. This reactivity arises from the complexity of its chemical surface functional group compared to those other surfaces. Iron particles will also promote the adsorption of metal ions. 

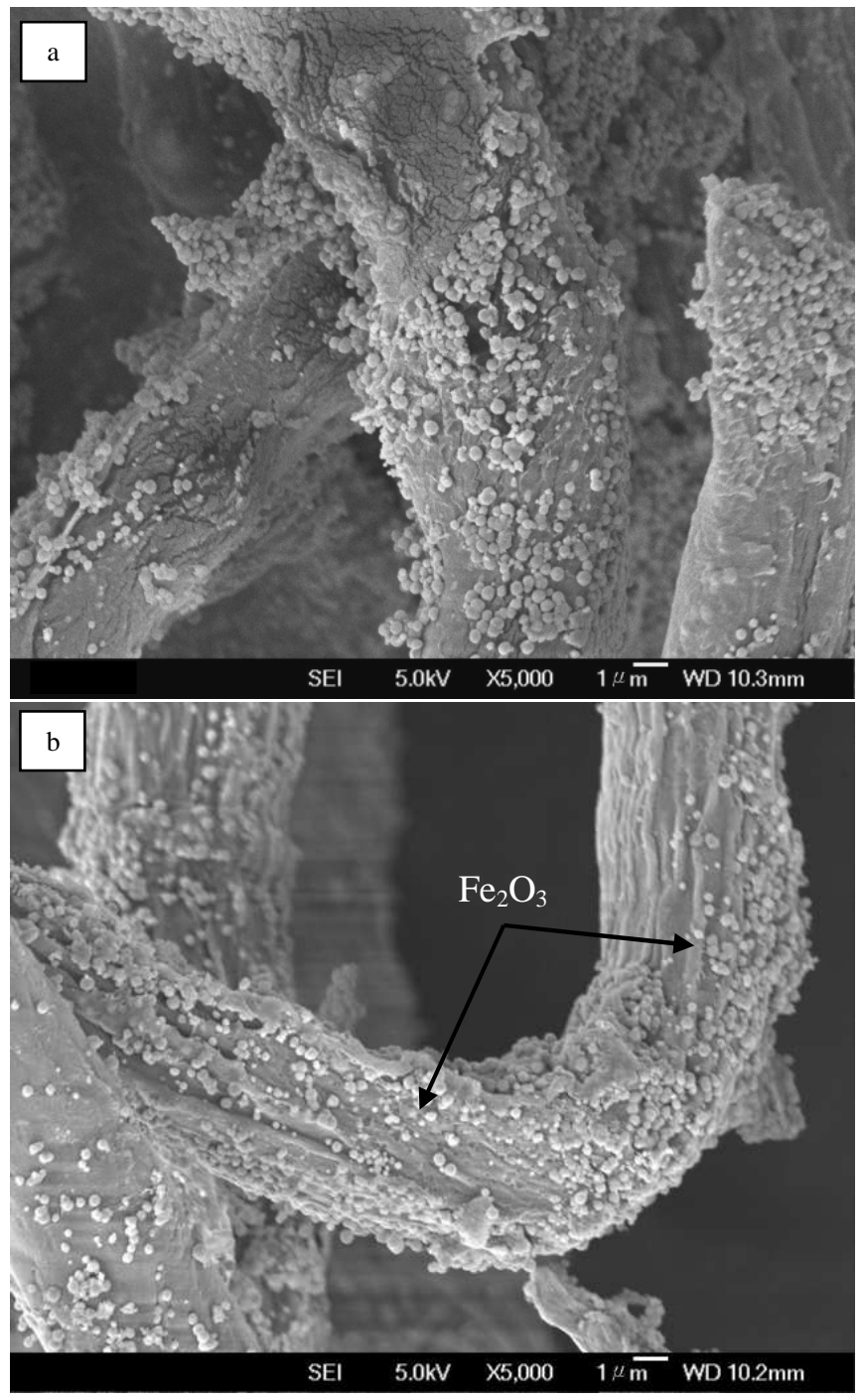

Fig. 2 FESEM image of biocomposites of a. EDB-M, b. EDB-MH

XRD analysis as shown in Fig. 3 are a pattern of ED fibers, ED after delignification, and biocomposites of EDB$\mathrm{M}$ and EDB-MH. The crystallinity of the ED fibers before and after treatment was shown. The XRD pattern shows a typical spectrum of cellulosic crystalline material, having amorph peak amorph at $2 \theta=16,2$ and crystalline peak at $2 \theta$ $=22.6$. The main crystalline peak is appropriated as indicative of highly organized crystalline cellulose, while the amorph peak determines of a minor organized polysaccharide structure and its assigned to broad peak with low angle [10]. The treatment of ED fibers with alkaline treatment, biocomposite using iron (III) nanoparticles, even by added and without the addition of amino group will change the crystalline structure.

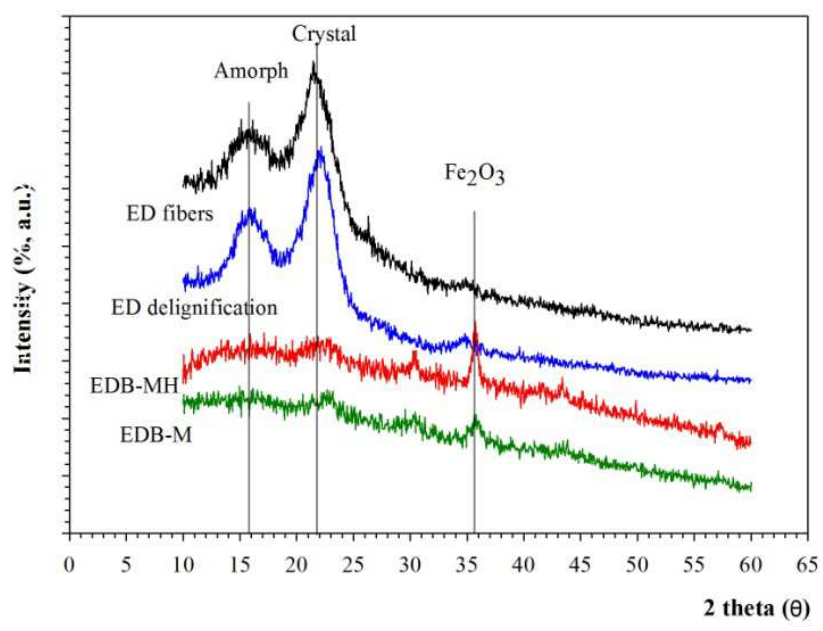

Fig. 3 XRD analysis of ED fibers, ED delignification, EDB-M, and EDB$\mathrm{MH}$

The alkaline treatment of ED fibers improves their crystalline structure. It is noted that enhances the crystallinity index to $72,75 \%$ using $1 \%$ of $\mathrm{NaOH}$ solution. This is due to the chemical reagents react to the chain ends on the surface of the crystalline structure and reducing the amorphous product like cellulose, hemicellulose and lignin [13]. The formation of the iron (III) can also be seen in the XRD peaks of $\mathrm{Fe}_{2} \mathrm{O}_{3}$ around at 36. These lines are characteristic for spinels $\mathrm{Fe}_{2} \mathrm{O}_{3}$. Magnetic nanoparticles are adjacent to the standard pattern figure of crystalline hematite (JCPDS card 39-0664).

FT-IR spectra analysis of the ED fiber and modified ED fibers are shown in Fig. 4. The $\mathrm{C}-\mathrm{H}$ stretching vibration of the ED fibre and modified ED fibres are manifested through a strong peak at $2930 \mathrm{~cm}^{-1}$. The infrared spectra shown in this figure, revealed the absorption peaks at $580 \mathrm{~cm}^{-1}$ belonged to the stretching vibration mode of $\mathrm{Fe}-\mathrm{O}$ bonds in $\mathrm{Fe}_{2} \mathrm{O}_{3}$, even for EDB-M and EDB-MH, while at this peaks the stretching vibration did not appear for ED fibre and ED delignification, respectively. The present of amina on ED biocomposites is accordant with that of the band around $1540 \mathrm{~cm}^{-1}$ was due to the $\mathrm{N}-\mathrm{H}$ bending vibration in $-\mathrm{NH}_{2}$.

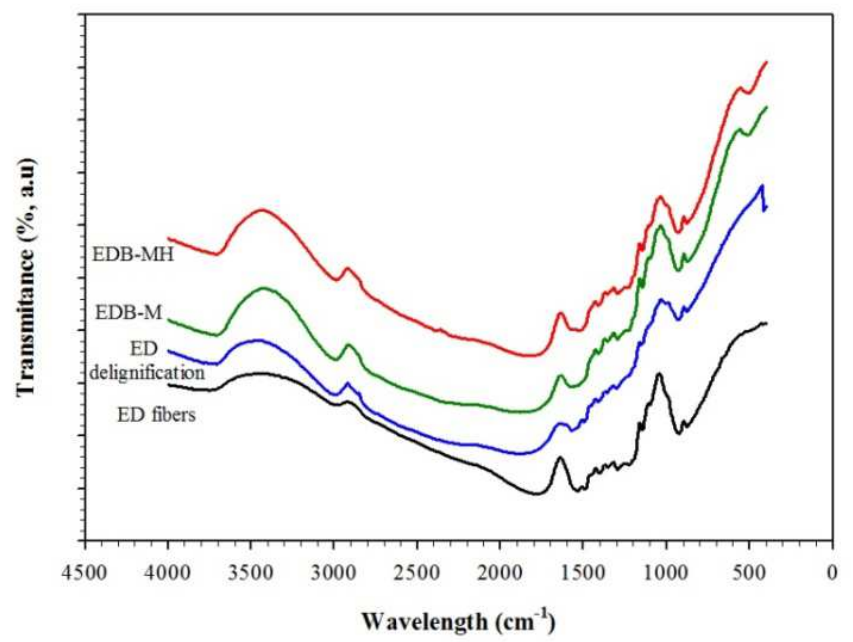

Fig. 4 FTIR analysis of ED fibers, ED delignification, EDB-M, and EDB$\mathrm{MH}$ 
B. Batch Adsorption Experiment of Sasirangan Textile Wastewater Treatment

\section{1) The Contact Time Effect on Adsorption}

Adsorption density mainly depends on the surface area available for adsorption and the composition of the adsorbent, whereas in this research modified by impregnating with iron (III) nanoparticles, without the amino group (EDB-M) and with the amino group (EDB-MH). Using the batch processes described in the experimental section, the dependencies of the adsorbed amounts of $\mathrm{Pb}^{2+}$, TSS, and color on their equilibrium concentrations in solution were measured. The contact time effect on the amount of $\mathrm{Pb}^{2+}$, TSS and color adsorbed onto adsorbent, EDB-M and EDB-MH, respectively were examined by conducting an experiment at ambient temperature, an adsorbent dose of $2.5 \mathrm{~g} / \mathrm{L}, \mathrm{pH}_{\mathrm{e}}$ of $6 \pm 0.2$, and shaking rate of $150 \mathrm{rpm}$.

Fig. 5 shows that during the first 30 minutes, $\mathrm{Pb}^{2+}$ uptake capacity increased significantly from $0 \mathrm{mg} / \mathrm{g}$ to $42.92 \mathrm{mg} / \mathrm{g}$ and $48.98 \mathrm{mg} / \mathrm{g}$ for EDB-M and EDB-MH, respectively. It was probably due to the diffusion taking place into the pores and or adsorb onto the surface of the adsorbent. Initially, all sites on the surface of the adsorbents were vacant and the $\mathrm{Pb}^{2+}$ concentration gradient was relatively high diffusing into and through the pore of the adsorbent [14]. Afterward, the $\mathrm{Pb}^{2+}$ uptake capacity slightly increased to $\mathrm{Pb}^{2+}$ uptake capacity of $44.82 \mathrm{mg} / \mathrm{g}$ and $49.92 \mathrm{mg} / \mathrm{g}$, respectively. Then finally to be attached to the adsorbent surface, caused by the decrease in the number of vacant sites on the surface of the adsorbent within 2 hours. It also maybe due to the availability of more adsorption sites with more functional groups resulting from the increase adsorption capacity for EDB-MH. The time beyond which no significant change in the adsorption takes places has been fixed as equilibrium time, then can be accepted as optimum contact time. The adsorption experiments were conducted in 2 hours reaction time to evaluate some parameter of $\mathrm{Pb}^{2+}$ removal.

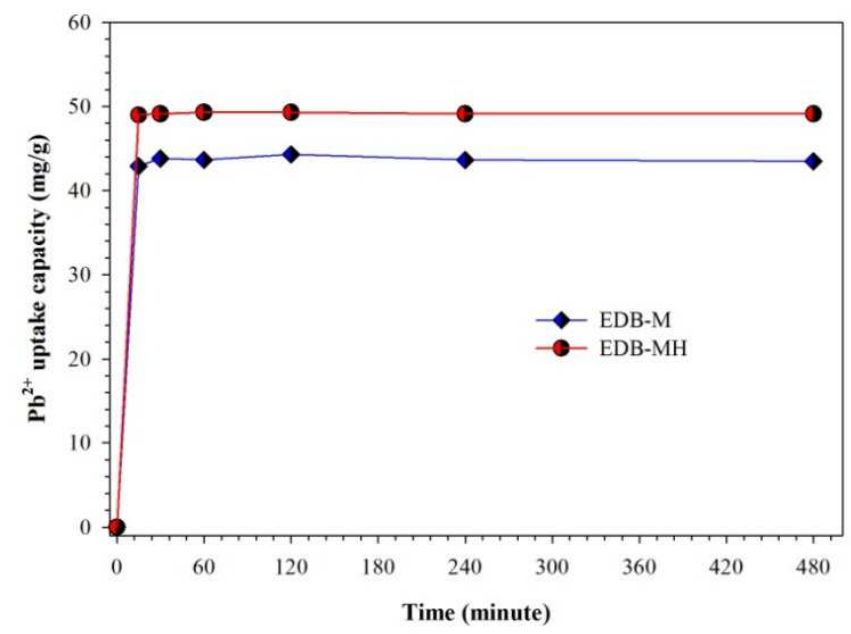

Fig. 5 Effect of contact time of $\mathrm{Pb}^{2+}$ adsorption onto EDB-M and EDB-MH, respectively at ambient temperature, adsorbent dose of $2.5 \mathrm{~g} / \mathrm{L}, \mathrm{pH}_{\mathrm{e}}$ of $6 \pm 0.2$, and shaking rate of $150 \mathrm{rpm}$

\section{2) The Equilibrium pH Effect on Adsorption}

The equilibrium $\mathrm{pH}$ effect on adsorption was investigated by conducting an experiment at ambient temperature, the initial $\mathrm{Pb}^{2+}$ concentration of ca. $100 \mathrm{mg} / \mathrm{L}$, the adsorbent dose of $2.5 \mathrm{~g} / \mathrm{L}$, shaking rate of $150 \mathrm{rpm}$, and contact time of 4 h. Fig. 5 shows that $\mathrm{pH}$ affected $\mathrm{Pb}^{2+}$ adsorption density over a wide $\mathrm{pH}$ controlled range of 4.0-12.0 0.2 .

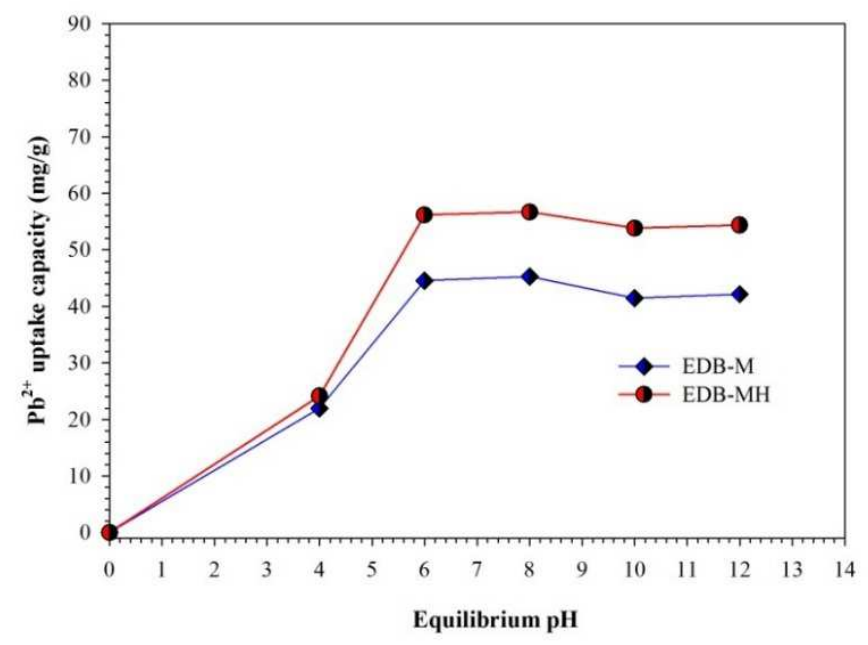

Fig. 6 The equilibrium $\mathrm{pH}$ effect on $\mathrm{Pb}^{2+}$ adsorption onto EDB-M and EDB-MH, respectively at ambient temperature, adsorbent dose of $2.5 \mathrm{~g} / \mathrm{L}$, and shaking rate of $150 \mathrm{rpm}$

Plotted in Fig. 6 shown that the $\mathrm{Pb}^{2+}$ adsorption envelops for the adsorbent was bell-shaped like typical oxyanions sorption curves. The lower value of $\mathrm{Pb}^{2+}$ adsorption density when the $\mathrm{pH}$ was low ( $\mathrm{pH}$ around 4 ) could be due to the excess of hydrogen ions surrounding the binding sites making adsorption process was unfavourable. $\mathrm{Pb}^{2+}$ and $\mathrm{H}^{+}$ ions compete with the active adsorption site and account for the lower adsorption uptake capacity [15]. Thus, $\mathrm{Pb}^{2+}$ adsorption density will increase with increasing $\mathrm{pH}$ around $6-8$ up to $44.21 \mathrm{mg} / \mathrm{g}$ and $55.62 \mathrm{mg} / \mathrm{g}$ for EDB-M and EDB$\mathrm{MH}$, respectively. The surface of the EDB-MH formation has many $-\mathrm{NH}_{2}$ groups that can coordinate with $\mathrm{Pb}^{2+}$ ions [7], then increased adsorption capacity compared without an amino group. The increase in $\mathrm{Pb}^{2+}$ removal as $\mathrm{pH}$ increases can be explained on the basis of a decrease in competition between protons $\left(\mathrm{H}^{+}\right)$and positively charged metal ions at the surface sites. At higher $\mathrm{pH}(\mathrm{pH}>8)$ due to metal solid hydroxide precipitation the $\mathrm{Pb}^{2+}$ ion seems remaining constant [15].

The equilibrium $\mathrm{pH}$ effect of the solution was also studied on TSS and color removal by EDB-M and EDB-MH, respectively at ambient temperature, an adsorbent dose of $2.5 \mathrm{~g} / \mathrm{L}$, and shaking rate of $150 \mathrm{rpm}$. Initial TSS of Sasirangan textile wastewater was of $1159.5 \mathrm{mg} / \mathrm{L}$. The solution $\mathrm{pH}$ was varied between 4 and 12 . The result of this effect is as shown in Fig. 7. The maximum percentage of TSS removal was obtained at $\mathrm{pH}$ 6-8around $91.9 \%$ and $98.1 \%$ removal, respectively for EDB-M and EDBMH.Various groups such as carboxylic and phenolic group present in wastewater interact with metal cations at low $\mathrm{pH}$, 
while hydroxyl and aliphatic hydroxyl groups interact at the elevated value of $\mathrm{pH}[17]$.

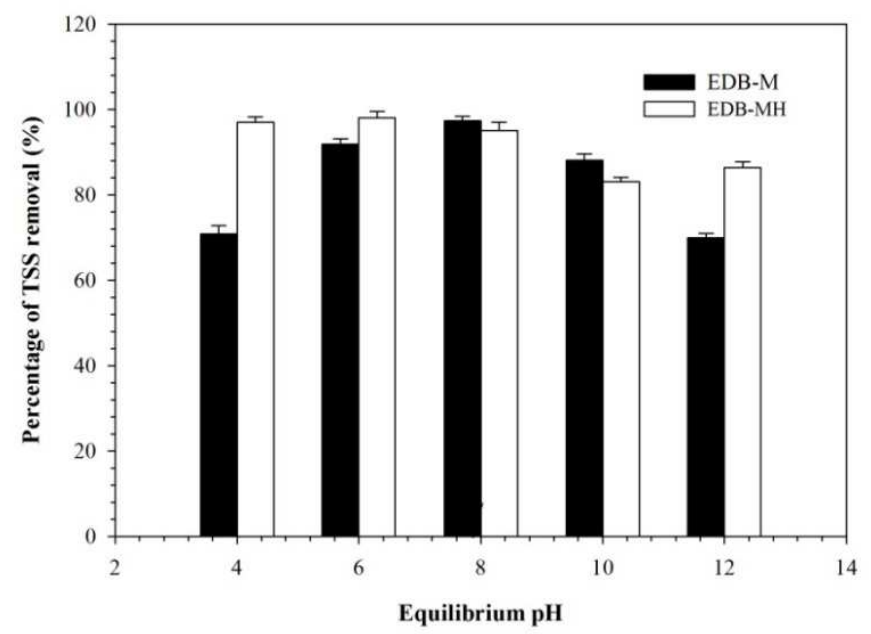

Fig. 7 The equilibrium pH effect on TSS removal using EDB-M and EDB$\mathrm{MH}$, respectively at ambient temperature, adsorbent dose of $2.5 \mathrm{~g} / \mathrm{L}$, and shaking rate of $150 \mathrm{rpm}$

The equilibrium $\mathrm{pH}$ effect of the solution was studied on color removal by EDB-M and EDB-MH, respectively shown in Fig.8. The initial color of Sasirangan textile wastewater was of $590 \mathrm{Pt} / \mathrm{Co}$. The solution $\mathrm{pH}$ was varied between 4 and 12. The high color reduction obtained at $\mathrm{pH}$ of $6-8$ around $96.7 \%$ and $97.86 \%$ removal, respectively for EDB-M and EDB-MH. This, in turn, neutralized the positively charged adsorbent surface with the existing iron oxide.

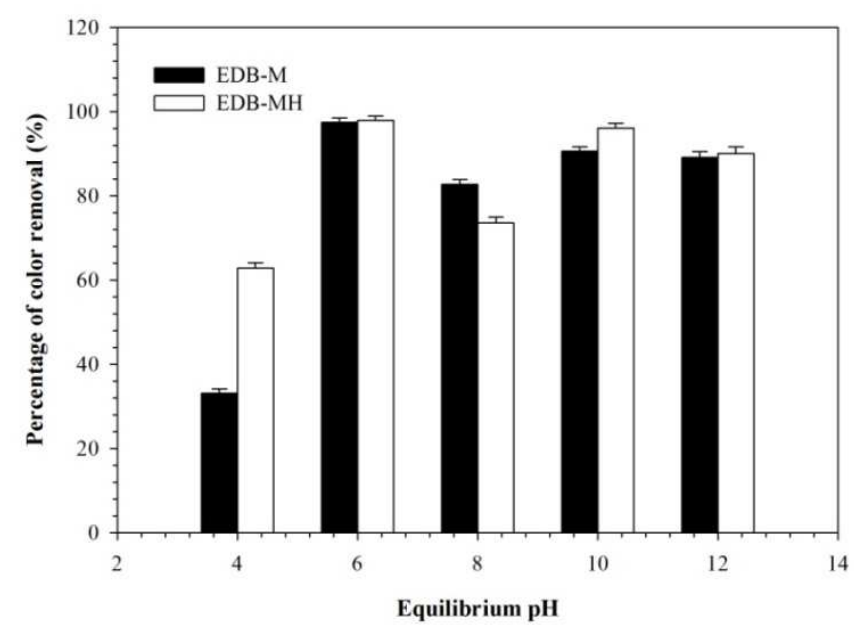

Fig. 8 The equilibrium $\mathrm{pH}$ effect on color removal using EDB-M and EDB$\mathrm{MH}$, respectively at ambient temperature, adsorbent dose of $2.5 \mathrm{~g} / \mathrm{L}$, and shaking rate of $150 \mathrm{rpm}$

The high color reduction at this range of $\mathrm{pH}$ is because of the abundance of $\mathrm{OH}^{-}$ions and ionic interaction between the positively charged active sites of the adsorbent. The adsorption of the color of dye may be explained to proceed via the electrostatic attraction between the positively charged protonated amino groups on the adsorbent surface of EDB$\mathrm{MH}\left(-\mathrm{NH}_{3}{ }^{+}\right)$and the negatively charged sulfonate groups $\left(\mathrm{SO}_{3}{ }^{-}\right)$of the dye [18]. A lower adsorption values at low $\mathrm{pH}$ is maybe due to attributed to the presence of larger number of $\mathrm{H}^{+}$ions, and ionic repulsion with the positive charged active sites of the adsorbent, then the adsorption capacity becomes decreases. There is no significant effect the adsorbent used for repeated uses. Regeneration of the adsorbents still reaching an efficiency of around $98 \%$ after 3 cycles.

\section{CONCLUSIONS}

This research study revealed that Eleocharis dulcis (ED) is a promising alternate to be used in the preparation of biocomposite materials with iron (III) nanoparticles for the reduction of $\mathrm{Pb}^{2+}$, TSS, and color from Sasirangan industrial textile wastewater. The characterization results shown by SEM, magnetic nanoparticles have been formed on the surface of ED fibre (EDB-M). The ED biocomposite with iron (III) nanoparticles (EDB-M) with diameter size around 30-50nm could be obtained. X-Ray Diffraction (XRD) analysis showed treatment of ED delignification was increased the porosity of the fibre, shown by increased Crystallinity Index (CrI) about $72.75 \%$. The ED biocomposites adsorbent had adsorption capacity for $\mathrm{Pb}^{2+}$ ions about $44.21 \mathrm{mg} / \mathrm{g}$ and $55.62 \mathrm{mg} / \mathrm{g}$. The effectiveness of reduced TSS was about of $91.9 \%$ and $98.1 \%$. Besides that, the colour intensity of color was decreased about $96.7 \%$ and $97.8 \%$ for the EDB-M and EDB-MH, respectively at equilibrium $\mathrm{pH}\left(\mathrm{pH}_{\mathrm{e}}\right)$ of 6 and equilibrium time of 2 hours. The positive charges on the surface of amine-group of the EDB-MH can promote significant electrostatic interaction with negatively charged sites on the surface of dye to high performance efficient adsorptive density capacity. More research of ED biocomposites is needed with respect to certain modifications and its potential for contaminant removal of contaminated water or wastewater.

\section{ACKNOWLEDGMENTS}

This research work was supported by Directorate of Research and Community Service, The Ministry of Research, Technology and Higher Education of Indonesia, the fund for Research University Grant (Number: 128/SP2H/LT/DRPM/ III/2016).

\section{REFERENCES}

[1] R.A. Overall, D.L. Parry, The uptake of uranium by Eleocharis dulcis (Chinese water chestnut) in the Ranger Uranium Mine constructed wetland filter Environ. Pollution 132 (2004) 307-320.

[2] A. Pela and E.Tokat, Color removal from cotton textile industry wastewater in an activated sludge system with various additives, Water Res. 36 (2002) 2920-2925.

[3] B.Y. Gao, Y. Wang, Q.Y. Yue, J.C. Wei, and Q Li, Color removal from simulated dye water and actual textile wastewater using a composite coagulant prepared by poly ferric chloride and poly dimethyl diallyl ammonium chloride, Sep. Purif. Technol. 54 (2007) 157-163.

[4] A.A. Ahmad and B.H. Hameed, Reduction of COD and Color of dyeing effluent from a cotton textile mill by adsorption onto bamboobased activated carbon, J. Hazard. Mater, 172 (2009) 1538-1543.

[5] V.V.B. Raoand S.R.M. Rao, Adsorption studies on treatment of textile dyeing industrial effluent by flyash, Chem. Eng. J. 116 (2006) 77-84.

[6] T. E. Agustina, T. Aprianti, S.Miskah, Treatment of Wastewater Containing Hexavalent Chromium Using Zeolite Ceramic Adsorbent in Adsorption Column, Inter J. on Adv. Sci. Eng. Info. Tech., 7 (2017) $566-572$. 
[7] X. Liu, Q. Hu, Z. Fang, X. Zhang, and B. Zhang, Magnetic Chitosan Nanocomposites: A Useful Recyclable Tool for Heavy Metal Ion Removal, Langmuir 25 (2009) 3-8.

[8] I.F.Nata, G.W. Salim, and C.K. Lee, Facile preparation of magnetic carbonaceous nanoparticles for $\mathrm{Pb}^{2+}$ ions removal, J. of Hazard Mat. 183 (2010) 853-858.

[9] L.Wang, J. Bao, L. Wang, F. Zhang, and Y, Li, One-pot Synthesis and Bioapplication of Amine-functinalized Magnetite Nanoparticles and Hallow Nanosphere. Chem. Eur. J. 12 (2006) 6341-6347.

[10] APHA, AWWA, WEF, Standard methods for the examination of water and wastewater, 19th edition(1995), APHA: Washington, DC.

[11] L Ghali, S Msahli, M Zidi, and F Sakli, Effect of pre-treatment of Luffa fibres on the structural properties, Materials Lett. 62 (2009) 61-63.

[12] J. Lamaming, N. H. Sharudin, R. Hashim, and O. Sulaiman, Characterization of Cellulose Microfibers Isolated from Rubberwood (Hevea brasiliensis), Inter J. on Adv. Sci. Eng. Info. Tech., 6 (2016) 170-174.

[13] R.M. Ali, H.A. Hamad, M.M. Hussein, and G.F.Malash, Potential of using green adsorbent of heavy metal removal from aqueous solutions: Adsorption kinetics, isotherm, thermodynamic, mechanism and economic analysis, Ecol Eng. 91 (2016) 317-332.
[14] R.R. Mohammed, M.R. Ketabachi, and G. McKay, Combined magnetic field and adsorption process for treatment of biologically treated palm oil mill effluent (POME), Chem. Eng. J. 243 (2014) 3142.

[15] E.S. Priya, and P.S. Selvan, Water hyancinth (Eicchornia crassipes)An efficient and economic adsorbent for textile effluent treatment-A review, Arab. J. of Chem. (2014), article in press.

[16] F. Boudrahem, F.A. Benissad, and A. Soualah, Adsorption of Lead(II) from Aqueous Solution by Using Leaves of Date Trees As an Adsorbent, J. Chem. Eng. Data 56 (2011) 1804-1812.

[17] M. Irfan, et al., The removal of COD, TSS and colour of black liquor by coagulation-flocculation process at optimized $\mathrm{pH}$, settling and dosing rate, Arab. J. of Chem., (2013), article in press.

[18] A.A. Atia, A.M. Donia, W.A. Al-Amrani, Adsorption/desorption behavior of acid orange 10 on magnetic silica modified with amine groups, Chem. Eng. J. 150 (2009) 55-62. 